\title{
BINARY BATTLESHIP: AN ACTIVE-LEARNING ACTIVITY FOR RECRUITING STUDENTS IN COMPUTER-RELATED FIELDS
}

\author{
Ronnie Fanguy, Nicholls State University, Ronnie.fanguy@nicholls.edu \\ Lori Soule, Nicholls State University, Lori.Soule@nicholls.edu \\ Ray Giguette, Nicholls State University, Ray.Giguette@nicholls.edu \\ Betty Kleen, Nicholls State University, Betty.Kleen@nicholls.edu
}

\begin{abstract}
This paper describes both the progression of an active-learning activity used in introductory computer information systems classes and its recent use as a hands-on activity for recruitment of high school students. The authors used the new and improved learning activity to engage high school students visiting campus for a College of Business seminar day. A brief survey was administered to those with signed parental permission to measure student reactions to the activity. Overall, positive opinions were expressed about the learning activity, and students viewed the activity as fun.
\end{abstract}

Keywords: Active-Learning, Computer Games, Recruitment

\section{INTRODUCTION}

Many academic departments in colleges across the country are feeling the pressure of shrinking budgets while simultaneously needing to increase enrollment. Strategies for recruitment are always of concern, as engaging today's students is arguably much more challenging than engaging students a decade or two ago. The authors of this paper teach at a medium-sized public university in the south. While numerous recruiting strategies are being employed in general by the university, the College of Business has recently established its own additional recruiting strategies. A series of business seminar days in which area high schools bring students to campus for a morning of seminars in various business disciplines offers students an opportunity to learn about accounting, finance, management/marketing, and computer information systems. The CIS faculty specifically wanted to engage the students in something they would perceive as fun as they learned a little about computer information systems.

This paper describes the active-learning activity that has been improved from its first 2006 version used in introductory computer information systems classes and that is now used in the high school seminar events. The authors also chose to survey students to gather their opinions of the activity and have reported the results in the data analysis section of this paper.

\section{LITERATURE SURVEY}

In recent years, there have been many studies regarding the recruitment of majors in computing fields such as Computer Science, Information Technology, and Information Science. The most common reason students give for not choosing these majors is that they appear uninteresting (Walstrom et al 2008). Student opinions, however, are often based on misinformation, of both the subject matter and possible career paths (Carter 2006; Myers \& Beise 2001; Stam et al 2009). This is in part a result of fewer students taking computing courses in high school (Cutts et al 2007). However, research also shows that the more information students have concerning computing degrees, the more positive their views become (Breaugh 2013; Carter 2006).

This suggests that two important goals of recruiting are to give students specific subject information and to highlight interesting aspects of the field (Ferratt et al 2009). Unfortunately, successfully disseminating career information can 


\section{Issues in Information Systems}

Volume 18, Issue 2, pp. 148-157, 2017

be difficult. Research shows that prospective recruits quickly disengage from such presentations (Breaugh 2013). The challenge is to keep students' attention by presenting career-related information in an engaging manner.

Many students are drawn to computing by an interest in computer games (Carter 2006; Lakanen \& Isomöttönen 2013), and this interest can be exploited to engage their attention. Games have been used to foster interest in MIS courses (Dunphy \& Milbourne 2009), and encompass many of the factors that attract students to the discipline. Research indicates that students are more likely to major in MIS when it is taught in a way that is fun or unique, and that team-oriented games may be especially effective since student decisions are often influenced by a positive group dynamic (Rouibah 2012).

Many programs designed to introduce students to computing careers often include a video game component (Donathan et al 2011; Peterson \& Benham 2006). A gaming approach to teaching computer science has been popular for several years, and has been shown to appeal to both male and female students (Haller et al 2008). Wellconstructed educational games can increase student involvement, concentration, motivation, and ability to address complexity (Michael \& Chen 2006), resulting in more sustained learning (Connolly et al 2012).

The literature includes many examples of games successfully being used to recruit students and even to attract job applicants (Klein \& Groh 2016; Chow \& Chapman 2013). One study showed that presenting company-related information in a game-like manner increased the likelihood prospective candidates would apply for a particular job (Klein \& Groh 2016). Recruitment programs featuring short informational sessions followed by related game-like activities (a structure employed by the authors of this current 2017 paper), can both change students' perceptions of a degree and increase the likelihood that they will consider it as a major (Egan 2010).

An additional benefit of using games as recruiting tools is that they can impart a more positive impression of the degree program or even of the institution (Chow \& Chapman 2013). Clever use of games may make a program appear innovative and technologically advanced. This can in turn attract students, especially millennials, who see themselves as innovative and who seek an innovative educational experience (Klein \& Groh 2016).

The findings of this brief literature review support the use of an active-learning component in a CIS high school seminar.

\section{PURPOSE AND METHODOLOGY}

The purpose of this paper is twofold:

1. To describe changes that have been made to improve a hands-on active learning telecommunications project

2. To determine whether participating high school students had a positive opinion regarding the hands-on active learning project.

The project was submitted to and approved by the University's Human Subjects Institutional Review Board (HSIRB). Because the participants in the seminars are all high school students and most likely under the age of 18, it was necessary to devise some type of parental consent form. The College worked as a whole and designed a single form that would cover any type of survey and ensuing data analysis for published research in any of the day's activities. Teachers at the participating schools sent those forms home with students, along with the general parental permission form for the field trip.

In addition to gathering demographic information of gender and grade classification, the authors designed a very simple survey in which students were asked to respond to four questions, using a Likert-type scale.

1. Did the student have fun at the session?

2. Did the session help the student to better understand the basic concepts underlying computer communications?

3. Was the communications protocol used for the game easy to understand? 
4. Did the session increase the student's interest in majoring in computer information systems or computer science in college?

\section{HISTORY OF THE TELECOMMUNICATIONS PROJECT}

In 2006, the authors developed a hands-on, active learning telecommunications project that was designed to be used within Introductory Computer Information Systems classes taken by a mix of various business majors (Fanguy, Kleen, \& Bhutta, 2006). The intention behind this project was to provide students with an example of how communication between computers takes place. The project utilizes two Tupperware terminals-outfitted with electronic switches, buzzers, LEDs and appropriate connections - attached to one another via a 20 -foot long printer cable. This homemade electronics system enables electronic communication by supporting the transport of 5 bits in parallel from terminal to terminal. Additionally, an electronic buzzer at each terminal aids in getting participant attention and can be used to add another dimension to the communication process. Recently, the authors have upgraded and repurposed this invention as a recruiting tool-adapting the project so as to allow high school students to play rounds of a simple game that helps to illustrate basic telecommunications concepts.

After using the original system with several groups of students, the authors were able to identify a number of improvements. While the electronic connections and setup follow the exact same electronic schematic as the original, the upgrades performed improve the system's stability and ease of use. One upgrade includes the use of a salvaged computer and printer (both set aside as surplus equipment) instead of Tupperware - a change which drastically improves the stability of the system and lessens problems in actually getting it set up and running properly at project time. The flexibility of the original terminals — or the movement of electronics components that this flexibility allows - sometimes leads to short circuits and loose connections breaking free. This change to a more rigid terminal not only helps to ease this problem but also enables a much more stable power source. While a 9-volt battery provides power to the Tupperware-based system, the surplus computer's power supply is utilized in the newer version. Thus, the system's power is much more reliable. In the original version, push button switches were used to control the sending of electronic messages. The toggle switches used in the upgraded version drastically reduce finger fatigue and simply make message sending easier for the participants.

\section{Game Playing Using the Equipment}

This system enables communication by allowing students to send 5-bit messages back and forth. One of the bits is reserved to distinguish between control messages and binary numbers. With the remaining 4 bits, the numbers $0-15$ may be sent back and forth. Networking protocols were developed to assign meaning to specific bit sequences. Without going into detail, a correlation is made between how students will use these protocols and how actual networking protocols such as TCP/IP accomplish their assigned task.

The games played with the system have changed over time. Initially, the system was used to play a guessing game. One group would ask the other to guess their average age, average number of hours taken this semester, or average number of family members. Binary-coded digits were used to make guesses, and responses indicated whether the guess was too high, too low, or correct. By and large, this initial version was a flop. In general, it never really went over very well with students. Subsequently, the game was modified to enable groups to play tic-tac-toe. In this version, the protocol was changed so that the binary numbers 1-9 refer to particular cells in the $3 \times 3$ tic-tac-toe game board, as shown in the table below. While this game worked out somewhat better, it was not until the development of the most recent game that the activity was considered a success.

Table 1. Numbers Assigned to Cells on a 3 x 3 Game Board

\begin{tabular}{|l|l|l|}
\hline 1 & 2 & 3 \\
\hline 4 & 5 & 6 \\
\hline 7 & 8 & 9 \\
\hline
\end{tabular}

Over the past year, the authors have modified the game to allow students to compete in rounds of Binary Battleship, a simplified version of the popular Milton Bradley naval strategy game. Using the same $3 \times 3$ game board that was 


\section{Issues in Information Systems}

Volume 18, Issue 2, pp. 148-157, 2017

used for tic-tac-toe, student groups decide upon their placement of two battleships, each of which must fit within two adjacent squares on the game board - either up and down, left to right, or diagonally. Afterward, groups alternatively shoot at specific game board locations by sending a single binary-encoded message. After each shot, the message must be decoded and interpreted in order for the other team (the shot-at team) to respond as to whether the shot was a hit, a miss, or the dreaded "You sank my battleship!" response. Game play continues until one group sinks both of the other group's battleships.

This newest iteration of game play seems to work very well. In general, high school student groups tend to intuitively grasp how to play. This is partially accomplished by a much simpler protocol. Previous games required students to send more than one 5-bit sequence in order to play. The protocol for Binary Battleship is simplified so that only a solitary 5-bit sequence is necessary for guesses and for responses. To further ensure that game play proceeds smoothly, each group is assigned their own CIS consultant - a CIS major who is familiar with the system and the game. Additionally, this game seems to be more of a challenge that participants enjoy. There is less mental stimulation involved in guessing a higher or lower number (as in the initial game). And, tic-tac-toe (the next game developed) did not have the same impact. Binary Battleship challenged participants as they tried to logically determine where their opponents had positioned their game pieces. It was a task that was simple to understand but required strategy to master. Those participating often pushed for a rematch as they mentally developed an improved strategy for the next game. Due to time limitations of the CIS segment structured as part of the College of Business seminars for high school students, attendees were typically only able to play two rounds.

\section{Recruiting Efforts}

The university's College of Business is in the process of reaching out to business programs at local high schools to invite them to participate in a series of business-related seminars. In Fall 2016, two high schools participated, and in Spring 2017 three high schools participated. Plans are in place to continue this program into the future. After arriving on campus, visiting students receive a brief welcome from the Dean and then progress through 30-minute sessions on Finance, Accounting, Management/Marketing, and Computer Information Systems. The authors, who are responsible for the Computer Information Systems session, organized their session around the Binary Battleship game to illustrate the basics of computer networking.

Before beginning the Binary Battleship game itself, students receive a brief explanation of the activity and the corresponding telecommunications concepts. In this introduction, students are informed about career paths, the high placement rate in computer-related fields, and some of the interesting projects that are ongoing within the department. After the Binary Battleship game, students are challenged to recall some of the facts which were introduced (giving faculty a chance to reinforce the positive impression that the seminar was intended to do). Anecdotally, this approach seems to succeed in informing students about the benefits of computing degrees before they disengage - a problem particularly noted from the survey of literature. In the data analysis section below, the authors explore the degree to which this resulted in increased interest in majoring in a computer-related field.

\section{Retention Focus}

Carrying out the game was facilitated by both CIS faculty and CIS students. The CIS faculty worked with the CIS club and with selected students enrolled in independent study courses to ensure that sufficient help was available when the sessions were held. As much as possible, CIS students were allowed to participate by doing the following:

- set up and test the system in preparation for the sessions,

- present the networking concepts and game instructions to the high school students,

- serve as CIS consultants to aid groups in gameplay, and

- conduct the surveying of students.

By giving CIS majors these responsibilities, the authors believe more is gained than just having help in implementing this event. The authors intuit that those participating feel a stronger sense of belonging and purpose because of the role which they played in this activity. By and large, this was not just another item on a to-do list that needed to be checked off. Rather, it was a way to reach out to younger students and help them grow in 


\section{Issues in Information Systems}

Volume 18, Issue 2, pp. 148-157, 2017

understanding of these CIS-related concepts, to help a younger generation have fun and experience excitement within their chosen field. Those students participating demonstrated a higher degree of connectedness than the many students who simply show up for classes and then leave immediately afterwards. Due to this, the department faculty are hopeful and expectant that these efforts will result in an increase in retention of these students within the university.

\section{DATA ANALYSIS}

This study collected survey data from those high school students attending High School Binary Battleship sessions which were held on multiple Friday mornings during the Spring 2017 semester. Because most students were under the age of 18, parents had to sign a form authorizing the authors to gather and report on the opinions of their children via the HSIRB-approved survey instrument. For the first school visit on March 24, 2017, 16 students were in attendance. However, their teacher neglected to get parental permission so none of the data captured could be used in this study.

The second group of high school students visited on March 31, 2017. Thirty-seven students were in this group. However, eight students did not get permission from their parents to participate in the survey, so the authors could only use data from the remaining 29 students.

The third group of high students visited on April 7, 2017. This group consisted of 28 students, and all had received parental permission to participate in the survey.

\section{Student Demographics}

A total of 57 students participated in the survey after receiving parental permission. Of these students, $49.1 \%$ were male and 50.9\% were female. Most of the students were juniors (45.6\%) and sophomores (43.9\%), although there were minimal seniors $(8.8 \%)$ and freshmen (1.8\%). Almost all the students used a smartphone $(94.7 \%)$ with only a small handful not using a smartphone (5.3\%).

\section{Student Opinions}

Students were asked four Likert-type questions. The choices for the answers ranged from 1, which represented "strongly disagree," to 5 which represented "strongly agree." Table 2 displays the mean and standard deviation for each of the Likert-type questions. Of the four questions, "I had fun at today's session" had the highest mean at 4.67. "This session has increased my interest in majoring in computer information systems or computer science in college." had the lowest mean at 3.67. Overall the students indicated positive opinions about their experiences in the CIS seminar.

Students overwhelmingly had fun during the activity, found that the game was easy to understand, and that their understanding was enhanced. While the authors do not expect that all students will feel drawn to major in computerrelated fields, this activity does produce positive results, on average, in terms of increasing interest in majoring in computer-related fields.

Table 2. Student Opinions, Likert-type Questions, $\mathrm{n}=57$

\begin{tabular}{|l|l|}
\hline \multicolumn{1}{|c|}{ Survey Question } & \multicolumn{1}{c|}{ Results } \\
\hline Q1: I had fun at today's session & $\begin{array}{l}M=4.67, \\
S D=0.546\end{array}$ \\
\hline $\begin{array}{l}\text { Q2: This session helped me to better understand the basic concepts underlying } \\
\text { computer communications. }\end{array}$ & $\begin{array}{l}M=4.28, \\
S D=0.701\end{array}$ \\
\hline Q3: The communications protocol used for the game was very easy to understand. & $\begin{array}{l}M=4.30, \\
S D=0.778\end{array}$ \\
\hline $\begin{array}{l}\text { Q4: This session has increased my interest in majoring in computer information } \\
\text { systems or computer science in college. }\end{array}$ & $\begin{array}{l}M=3.67, \\
S D=0.778\end{array}$ \\
\hline
\end{tabular}




\section{Issues in Information Systems}

Volume 18, Issue 2, pp. 148-157, 2017

Student responses for questions one through four above are graphed in figures 1-4 to further visualize student response breakdowns. These results are in agreement with the published literature on recruiting. The authors have strived to engage students by challenging them to play a competitive game in cooperation with other teammates. The survey results indicate similar positive impressions from students. Delivering subject-specific information on telecommunications and highlighting interesting aspects of the field in a short and quick manner that does not give students time to disengage from the presentation are other literature-based aspects that are important to success.

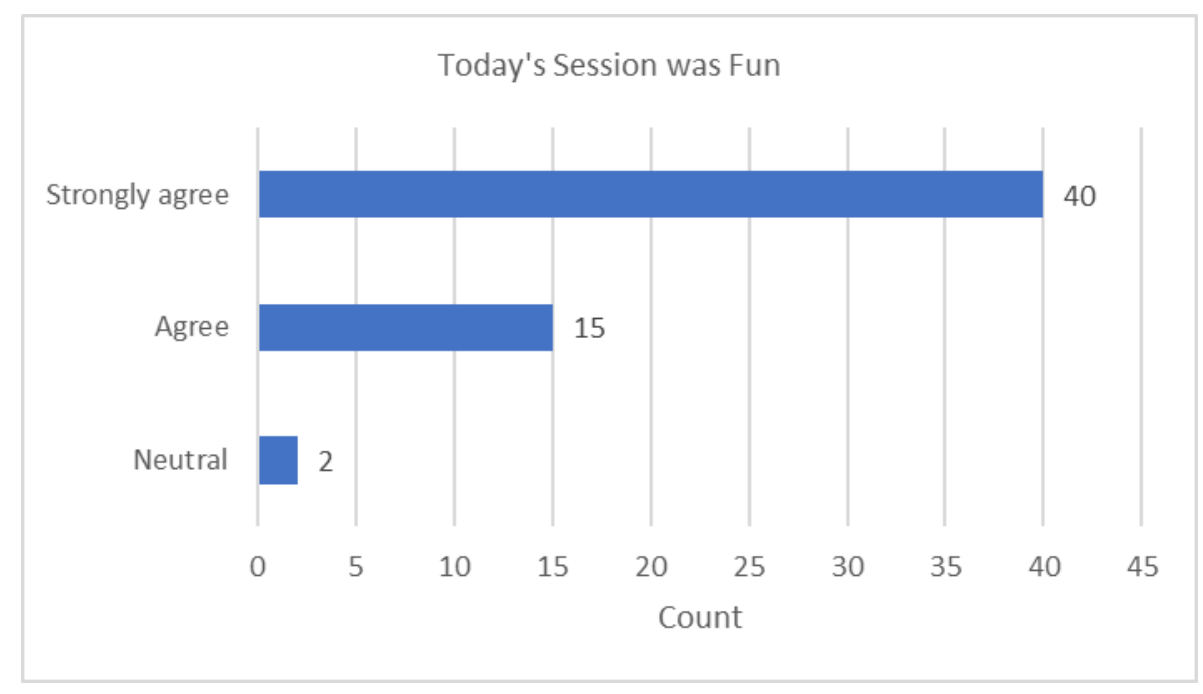

Figure 1. Student Opinion of Activity

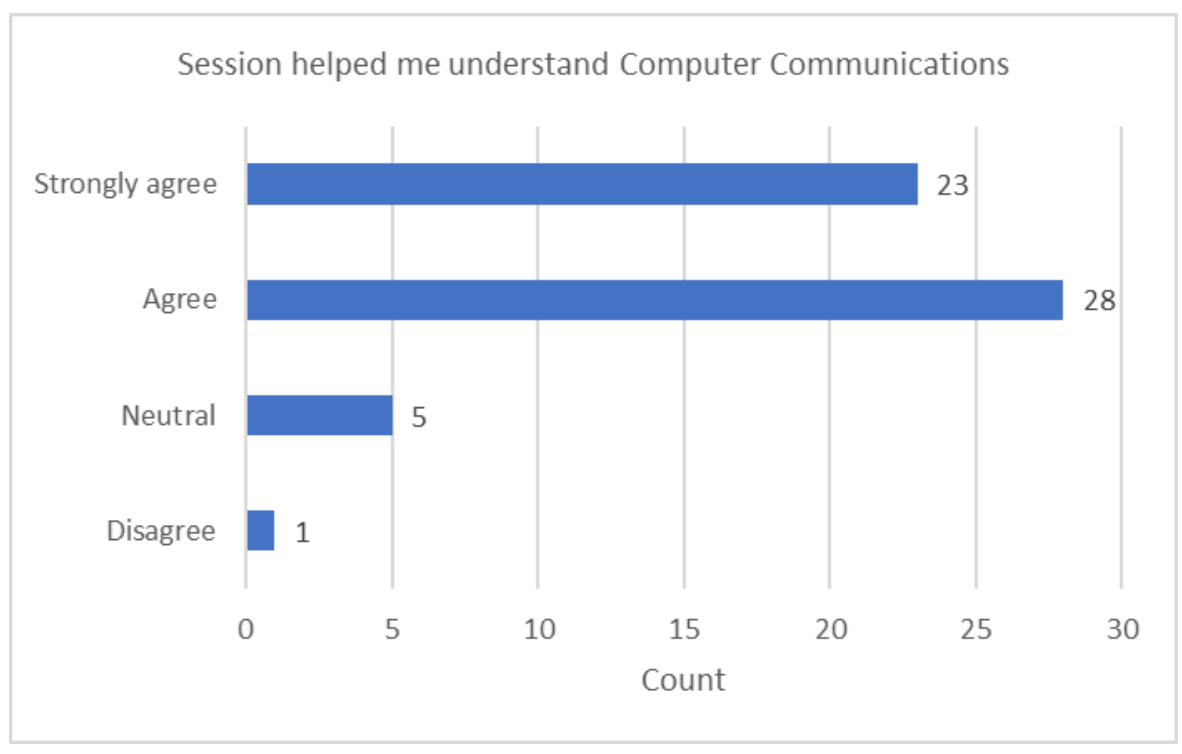

Figure 2. Student Opinion of Enhanced Understanding 


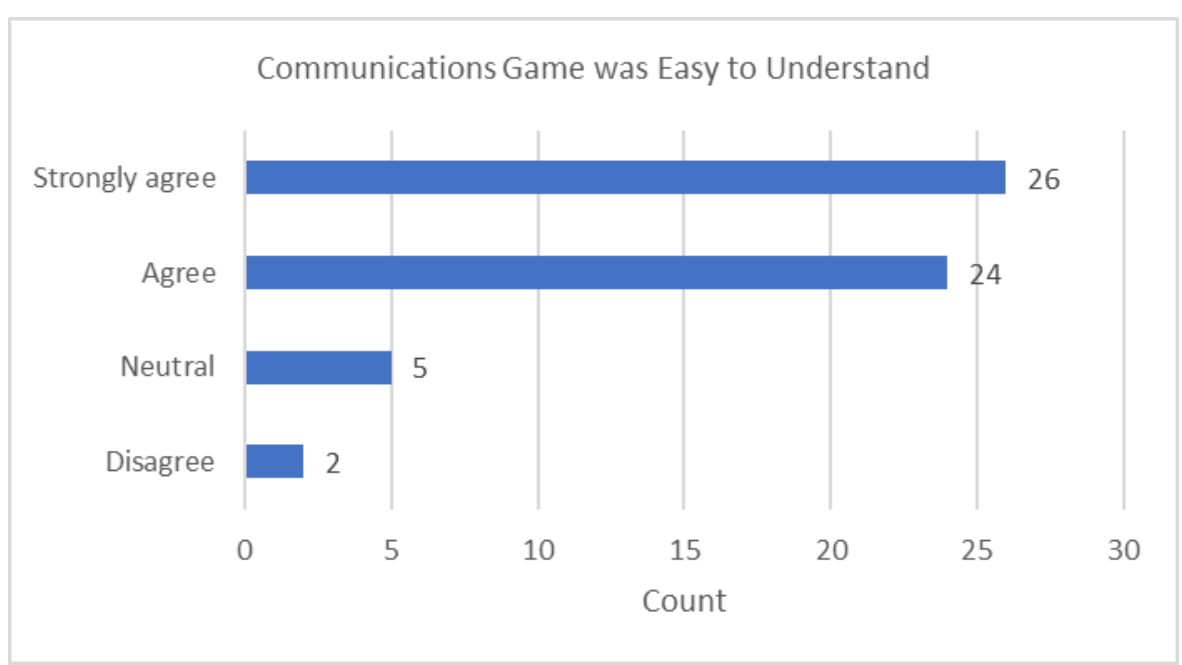

Figure 3. Student Opinion of Ease of Game Understanding

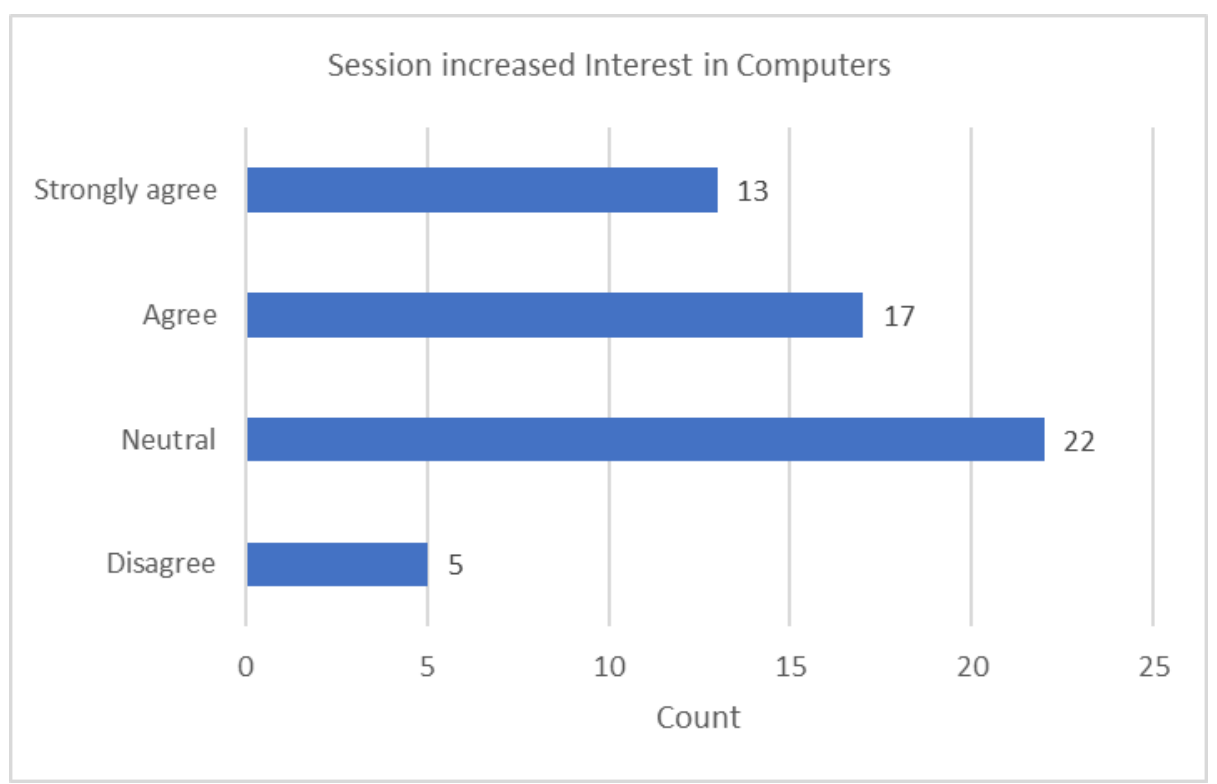

Figure 4. Student Opinion of Increased Interest in Majoring in a Computer-Related Field

\section{Independent Samples t-tests}

Mean responses were analyzed for differences among distinct groups of students. Independent samples t-tests were conducted to determine if any statistical differences exist.

Gender. The authors formulated hypotheses (H1-H4) about the differences in the mean of the dependent variable by gender. However, using independent samples t-test, none of the hypotheses were found to be statistically significant.

Classification. Due to the small number of freshmen and senior students, the authors combined the freshmen and sophomores into one group and the junior and senior students into another. The authors again tested formulated hypotheses $(\mathrm{H} 5-\mathrm{H} 8)$ using independent samples t-test. None of the hypotheses were found to be statistically significant. 
The authors were very happy to see that these statistical tests do not provide for any differences of opinion based on their demographics. The average positive opinions expressed of the learning activity held regardless of the students' demographic backgrounds.

\section{Regression}

Q1 as IV and Q4 as $D V$. A simple linear regression was calculated predicting students' increased interest in majoring in a computer-related field (Q4) based on their opinion of the day's session being fun (Q1). The regression equation was not significant $(F(1,55)=3.188, p>0.05)$ with an $R^{2}$ of 0.055 . The students' opinion of the day's session being fun cannot be used to predict the students' increased interest in computer-related fields.

$Q_{2}$ as IV and Q4 as $\mathrm{DV}$. A simple linear regression was calculated predicting students' increased interest in majoring in a computer-related field (Q4) based on whether or not the activity helped develop a better understanding of the basics of computer communications (Q2). A significant regression opinion was found $(F(1,55)=9.970, p<$ 0.003 ), with an $R^{2}$ of 0.153 . This statistically significant connection between these two variables informs us that students' predicted level of interest in computers is equal to $1.436+0.521 *$ (opinion of the session helping to improve understanding of the basic concepts underlying computer communications). Students' average level of interest in majoring in a computer-related field increased 0.521 points for each point increase in better understanding as a result of the activity. This result is quite encouraging as it offers confirmation that faculty efforts are yielding the results desired. It is not surprising, however, as it is in line with published research on this issue (see Ferratt et al 2009).

\section{Open Ended Comments}

In addition to completing the specific CIS questionnaire discussed above, many of the students also completed the College of Business survey designed to obtain feedback about the entire day's activities, including all four of the discipline-specific short seminars they had attended. "What was your favorite part of the workshop series?" was one of the open-ended questions in that survey. Of the 40 students that responded to the question, $47.5 \%$ of the students had "battleship," "binary battleship," "CIS," or "computer games" as their answer.

\section{CONCLUSIONS AND RECOMMENDATIONS}

Overall the activity worked extremely well, and students enjoyed the telecommunications activity. Aiming to further improve upon this success, the authors have the following two specific changes planned: expand the number of Binary Battleship playing stations and more effectively manage CIS consultants. The expectation is that these changes will result in the following three advantages: fault tolerance, capacity expansion, and smoother session flow.

Despite early setup and testing, one of the biggest concerns in carrying out the sessions relates to whether the equipment will actually function correctly. In the initial version, this was much more of a problem, and bad experiences from early attempts linger in the authors' memories. In the most recent set of Spring 2017 sessions, the equipment proved reliable and functioned properly. However, in one of the Fall 2016 sessions faculty were unable to get the game stations setup and running properly - some of the electronic switches would not appropriately light up the LEDs. A quick low-tech backup plan of using binary codes printed on flash cards enabled the completion of the session. But, the effect on the participants and their level of engagement was significantly reduced. Building additional playing stations will provide a much better fallback position. If technical issues occur, faculty can simply utilize another terminal and place the faulty unit aside to be repaired at a later time. Thus, faculty will be able to tolerate a greater amount of error within the session/system; thereby, a higher degree of fault tolerance is achieved.

Currently, two Binary Battleship playing stations (an upgraded version of the original and the completely rebuilt model described in a previous section) are being used. With these, seminar facilitators can support two or four teams of students participating at one time - or up to 12 students playing concurrently with three students per team. (With more than three students in a team, it is difficult for everyone to participate.) Thus, the session capacity is currently limited to a dozen students. Additional playing stations will allow more groups of students to play at the same time, and a higher capacity will be achieved. 
In order to aid in the smooth flow of sessions, faculty employ the use of Computer Information Systems students. In early meetings, faculty expected that simply getting additional help to show up with minimal instruction would be helpful. However, this was not the case. During one of the sessions, a number of CIS students attended to earn the bonus points which were promised. Simply being there to earn the points, they did not add much benefit to the event. Furthermore, they may have actually had a detrimental effect. Participants were more hesitant to fully immerse themselves in the game while they were being stared at by the sideline spectators.

With this lesson learned, Spring 2017 sessions ran more smoothly. CIS students were recruited for their assistance in the event, but they were required to actually participate in a full tournament of play at a CIS club meeting. This helped to ensure that they had a good understanding of how the game is played. During the actual sessions, these practiced CIS students were assigned to serve as consultants to participating groups of high school students. With this change, full participation was much more prevalent, and the session flowed more smoothly overall.

In subsequent semesters, faculty plan to manage the CIS consultants even more closely. Faculty will meet with volunteering CIS students to clearly explain expectations beforehand and will closely monitor the interactions of the CIS students with the game participants. This change is based upon the observation that a higher level of engagement was achieved when the CIS consultants were much more integrated into the group-more active in overseeing the game and clarifying misunderstandings. When CIS consultants take on the role of error checker during game play, it is very beneficial. If the team incorrectly sends the wrong bits to represent their message, if the bits that were sent do not match the bits received, if the receiving team misinterprets the binary code received, and other similar situations can all cause frustration among the participants. Sessions run much more smoothly if these errors are immediately identified and fixed. At the same time, an additional benefit arises. When participants see the error and its correction, a perfect opportunity is created to discuss the general concept of network errors in the context of telecommunications. Managing CIS consultants more carefully to ensure that they understand the importance of being on top of catching these errors before they negatively affect the game at hand will be helpful to session success.

It is clear that faculty are challenging the University's CIS students to step up to a leadership role, expecting them to get their team on its feet and performing. Communication skills are being sharpened as they explain gameplay, clarify misconceptions, and help their team successfully compete in the event. This is a big challenge for many of the students. However, this event offers a great opportunity for skill improvement in this area.

The authors view this telecommunications activity a success, believing that exposure to the basic telecommunications concepts covered in this engaging activity will help to not only increase knowledge but also spark heightened interest in computer related fields - hopefully giving positive results from these recruiting efforts. By involving CIS majors and relying on them, faculty see a deeper level of involvement, responsibility, and skill development - hopefully resulting in improvements in the department's retention efforts. Being an important part of CIS overall recruiting and retention initiatives, Binary Battleship competitions will continue to be offered to high school students in future academic terms. By directly addressing the issues which literature points out as keyproviding information about career paths and giving subject-specific information all within a team-oriented gaming challenge - we are expecting positive results.

\section{REFERENCES}

Breaugh, J. (2013). Employee recruitment. Annual Review of Psychology, 64(1), 389-416.

Carter, L. (2006). Why students with an apparent aptitude for computer science don't choose to major in computer science. Proceedings of the ACM technical symposium on Computer science education, Houston, Texas, 27-31.

Chow, S., \& Chapman, D. (2013). Gamifying the employee recruitment process. Proceedings of the First International Conference on Gameful Design, Research, and Applications, Stratford, Ontario, Canada, 9194. 
Connolly, T., Boyle, E., MacArthur, E., Hainey, T., \& Boyle, J. (2012). A systematic literature review of empirical evidence on computer games and serious games. Computers \& Education, 59(2), 661-686.

Cutts, Q., Brown, M., Kemp, L., \& Matheson, C. (2007). Enthusing and informing potential computer science students and their teachers. Proceedings of the ACM Conference on Innovation and Technology in Computer Science Education, Dundee, Scotland, United Kingdom, 196-200.

Donathan, K., Ericson, B., Tymann, P., \& Walker, H. (2011). Successful K-12 outreach strategies. Proceedings of the ACM technical symposium on Computer science education, Dallas, Texas, 159-160.

Dunphy, S., \& Milbourne, C. (2009). Using word scrambles as an information systems creativity warm-up exercise. Journal of Information Systems Education, 20(1), 5-12.

Egan, M. (2010). Recruitment of CS majors through a non-programmer's programming contest. Journal of the Consortium for Computing Sciences in Colleges, 25(6), 198-204.

Fanguy, R., Kleen, B., \& Bhutta, M.K. (2006). Using an experiential exercise to teach telecommunications concepts in a class for end users. 2006 IACIS Refereed Proceedings, Reno, Nevada, 64.

Ferratt, T., Hall, S., Prasad, J., \& Wynn, D. (2009). Why students choose MIS: What makes a major-job-career in management information systems interesting? Proceedings of the ACM SIGMIS Conference on Computers and People Research, Limerick, Ireland, 57-61.

Haller, S., Ladd, B., Leutenegger, S., Nordlinger, J., \& Paul, J. (2008). Games: Good/evil. Proceedings of the ACM technical symposium on Computer science education, Portland, Oregon, 219-220.

Klein, K., \& Groh, T. (2016). Innovative recruiting tools: Are serious games useful to attract digital natives of the millennial generation? Proceedings of the American Marketing Association Winter Educators' Conference, Las Vegas, Nevada, 26-28.

Lakanen, A., \& Isomöttönen, V. (2013) High school students' perspective to university CS1. Proceedings of the ACM Conference on Innovation and Technology in Computer Science Education, Canterbury, England, 261-266.

Michael, D., \& Chen, S. (2006). Serious Games: Games that Educate, Train, and Inform. Thomson.

Myers, M., \& Beise, M. (2001). Nerd work: Attractors and barriers perceived by students entering the IT field. Proceedings of the ACM SIGCPR conference on Computer personnel research, San Diego, California, 201-204.

Peterson, L., \& Benham, D. (2006). Overview of the CyberTech-ITEST Project: An initiative to attract and prepare under-represented students for tomorrow's careers in the computing Sciences. Proceedings of the ACM technical symposium on Computer science education, Houston, Texas, 453-455.

Rouibah, K. (2012), Understanding student drivers and obstacles toward MIS major from the perspective of an Arab country: the case of Kuwait. Issues in Information Systems, 13(2), 58-71.

Stam, K., Guzman, I., \& Stanton, J. (2009) RIP - the use of inoculation theory and online social networking for enhancing attractiveness of IT occupations. Proceedings of the ACM SIGMIS Conference on Computers and People Research, Limerick, Ireland, 139-142.

Walstrom, K., Schambach, T., Jones, K., \& Crampton, W. (2008). Why are students not majoring in information systems? Journal of Information Systems Education, 19(1), 43-54. 